\title{
PROBABI LITY OF DETECTION FOR IN FIELD THERMAL NON DESTRUCTIVE TESTING OF AIRCRAFT COMPOSITE STRUCTURES
}

\section{ABSTRACT FOR QIRT 2010}

\author{
By Pierre Servais ${ }^{*}$, Clemente Ibarra-Castenado**, Xavier Maldague**, Yann Gélébart*** \\ "PhD, Wallonie Aerotraining Network, Aerospace Engineering Department, \\ WAN, Chaussée de Fleurus 179, B 6041 Gosselies, Belgium, E-mail: pierreservais@skynet.be \\ **PhD, Postdoctoral Researcher/Professor, Laboratoire de vision et systèmes numériques, Chaire de recherche du \\ Canada, Université Laval, 1065, av. de la Médecine, Québec, Canada, Email : ibarraC@gel.ulaval.ca \\ ***PhD, NDT Engineer,Composite Level III UT, Quality Manager, Aircelle, \\ SAFRAN Group, Le Havre, France yann.gelebart@aircelle.com
}

Thermal NDT is now part of classic NDT methods to inspect the structural integrity of Aerospace Composite structures. As InfraRed Thermography (IRT) is now completely developed into recent international NDT standards like NAS410 (revision 2008) or EN4179 Edition 4 like other older NDT methods, it is really now time to investigate the reliability of IRT by studying the Probability of Detection (POD) and comparing with classic C-Scan Ultrasonic Testing. This paper will present the results of the study made by BelgiumFrance-Quebec research group which proposes to inspect the known 30 different composite structures of Aerospace Engine Nacelles which contains more than 100 defects and to try different techniques of IRT to build up original POD studies based on state-of-the-art technique to analyze the data using USAF methodology (as officially published in 1999).

To study POD for a new method, the number of specimen is very important as well as the human factor which plays an important role into the decision of acceptation/rejection for any thermal indication found during infrared testing of nacelle structures.

Aircelle is the European Leader for the conception, integration and manufacturing of Aircraft Engine Nacelles which contain big honeycomb composite structures ranging from a few $\mathrm{m}^{2}$ till more than $12 \mathrm{~m}^{2}$ for A380.

The purpose of this research is finally very important for the Aerospace Industry which will use the published data to be able to use more and more thermography as primary NDT method by knowing exactly the limits and detectability of the method when used out of laboratory with recent portable IR camera which are now available at the price of a good Ultrasonic Test Equipment. 